\title{
A Negociação de Jdentidade de Professor em Sala de Aula de Estágio de Língua Espanhola
}

\author{
The Negotiation of Teacher Identity in the Classroom of \\ SPANISH LANGUAGE
}

\section{Marcela de Freitas Ribeiro LOPES* Neiva Maria JUNG**}

Resumo: Este artigo tem como objetivo apresentar como é negociada a identidade de professor por uma estagiária, aluna do $4 .^{\circ}$ ano do curso de Letras/Espanhol de uma universidade do Centro-Oeste do Paraná. A fundamentação teórico-metodológica é a da Análise da Conversa Etnometodológica. Os dados de fala-em-interação são de duas turmas de Ensino Médio de um colégio público, no Estado do Paraná, nas quais foram filmadas e analisadas 9 horas/aulas. Em termos de resultados, acontecem conflitos, a professora da turma interfere na negociação da identidade de professora da estagiária, e os alunos colocam em xeque o seu status de quem sabe e de organizadora da fala-em-interação na aula.

Palavras-chave: Identidades sociais; Fala-em-interação; Formação de professores.

Abstract: This article aims at investigating how a trainee teacher, student of Portuguese and Spanish, at the State University of Midwest Parana, negotiates her teacher identity. The theoretical and methodological

\footnotetext{
* Mestre em Letras pela UEM (2009) e doutoranda do Programa de PósGraduação em Letras da UFRGS. Atualmente é professora assistente da UNICENTRO/Irati. Contato: marcelamail@yahoo.com.br

** Doutora em Letras pela UFRGS. Atualmente é professora associada da Universidade Estadual de Maringá, atuando na Graduação e Pós-Graduação em Letras.Contato: neivajung@yahoo.com.br
} 
approach is that of Conversation Analysis. By looking at the talk-ininteraction data, which consists of nine video recordings of two highschool classes, at a public school in the State of Parana, we observed that conflicts happen, the main teacher interferes with the negotiation of the trainee's teacher identity and students test her position as a teacher and as the talk-in-interaction organizer as well.

Key-words: Social identities; Talk-in-interaction; Teacher formation.

\section{Introdução}

A obrigatoriedade, desde 2005, do ensino de espanhol como disciplina curricular para o Ensino Médio, conforme a Lei n. ${ }^{\circ} 11.161$, de 5 de agosto de $2005^{1}$, nos leva a refletir sobre a formação de professores de língua espanhola, que Fernández (2005) considera uma grande dívida do governo brasileiro. Antes de a Lei mencionada entrar em vigor, o próprio Ministério de Educação do Brasil reconheceu a "necessidade de 210.000 professores de espanhol" (FERNÁNDEZ, 2005, p. 30).

Deste modo, é de extrema relevância olhar para a sala de aula de língua espanhola, em especial para estudar contextos de formação de professores de espanhol de cursos de graduação, os quais deveriam articular teoria e prática em todo o curso. A prática, no entanto, fica bastante restrita a uma disciplina chamada Estágio. Nessa disciplina, conforme mostra a experiência de professora de estágio de uma das pesquisadoras (LOPES), os graduandos/estagiários atuam por um período, algumas horas/aulas, em salas de aulas das escolas de Ensino Fundamental e Médio, buscando conhecimento prático de sala de aula para sua futura profissão. Ou melhor, os alunos dos dois últimos anos do curso têm uma expectativa de que, na disciplina de estágio, se constituirão professores, pois, além de terem a experiência prática, eles esperam ter, nessa disciplina, lições sobre como se relacionar com os alunos, como se portar na sala de aula e como ensinar tudo o que aprenderam até então.

${ }^{1}$ Disponível em: <http://www.planalto.gov.br/ccivil_03/_Ato2004-2006/ 2005/Lei/L11161.htm>. 
Diante disso, os estagiários, muitas vezes, se frustram. No limite entre ser estagiário e ser professor, precisam negociar conflitos na interação em sala de aula. Eles enfrentam uma situação em que as turmas não são “deles”, isto é, enquanto estão estagiando o professor da turma geralmente está presente na sala de aula. Os alunos, por sua vez, sabem que os estagiários irão reger a sala por algum período. Toda a circunstância é provisória e temporária. A negociação se dará em meio a todos esses elementos. É nesse contexto que surge o objetivo deste artigo: compreender como uma estagiária do curso de Letras/ Espanhol negocia e constrói sua identidade de professora na fala-eminteração, em suas aulas de estágio.

Para dar conta desse objetivo, que faz parte de um processo de entendimento da sala de aula e da formação de professor de língua espanhola no Brasil, o artigo encontra-se organizado da seguinte forma: na próxima seção, apresentamos como a Análise da Conversa Etnometodológica compreende a relação entre linguagem como ação social e identidades sociais; na seção dois, uma contextualização dos dados analisados; na seção três, a análise de dois excertos das aulas registradas e, por fim, algumas considerações finais.

\section{Fala-em-interação institucional}

Linguagem é entendida, neste artigo, como ação social. "A linguagem é uma realização local, colaborativa e intersubjetiva feita pelos membros com recursos linguísticos convencionalizados, mutuamente reconhecidos e socialmente partilhados." (MARKEE; KASPER, 2004, p. 495). E os falantes são concebidos

(...) como membros de comunidades, singulares e atrativamente complexas, cada uma das quais está articulada como um conjunto de instruções sociais, e através de uma rede de expectativas, crenças e valores morais não necessariamente sobrepostos, mas sim entrecruzados. (DURANTI, 2000. p. 21)

Nesse sentido, buscamos embasamento teórico nos estudos da Análise da Conversa Etnometodológica (doravante ACE) que tem sua origem na Etnometodologia e analisa as ações sociais dos 
participantes de uma interação, observando a sequencialidade dessas ações, turno a turno. $\mathrm{O}$ modo como os atores interpretam a realidade, como as pessoas entendem a sociedade e como elas demonstram esse entendimento na fala-em-interação é a chave da ACE.

Ação é a unidade analítica da ACE porque a ação social humana é indicial, isto é, a ação acontece quando um ator manifesta entendimento na sequencialidade de um turno da conversa e, novamente, outro ator completa a ação mostrando entendimento também do turno anterior. Toda essa sequência é construída, no contexto, de acordo com o que é significativo no momento da conversa. Portanto,

(...) os participantes precisam sempre se valer do andamento seqüencial da fala-em-interação para tomarem um turno de fala, o fazem sempre em relação ao que é relevante aqui-e-agora da conjuntura interacional, nisso revelam suas perspectivas do que foi feito antes e submetem esses entendimentos ao escrutínio dos interlocutores, o que pode efetivamente resultar em nova perspectiva conjunta, co-construída naquele aqui-e-agora interacional, justamente um dos grandes elementos produtivos do uso da linguagem, de natureza também indicial. (GARCEZ, 2008, p. 30)

A ACE descreve, desse modo, a ação social humana presente no uso da linguagem e, mais especificamente, na conversa cotidiana (SACKS; SCHEGLOFF; JEFFERSON, 2003), que, embora seja comum e corriqueira, é fundamental na vida social e é organizada. Levando isso em consideração, sabemos que, para o analista da conversa, "interessa articular como resultam as ações individuais para todos os efeitos práticos, o que para os participantes da fala-eminteração significa, necessariamente, lidar com o outro para produzir ação conjunta." (GARCEZ, 2008, p. 33).

Em uma sala de aula, essa ação conjunta pode se dar entre identidades de professor e de aluno. Dizemos "pode" por dois motivos: 1) não é o espaço sala de aula que diz que os participantes se engajam em uma fala-em-interação institucional de sala de aula; 2) as identidades negociadas na fala-em-interação de sala de aula podem ser muitas: 
identidade de professor, identidade de aluno, identidade de pesquisador, identidade étnica, identidade de mãe, identidade de filho, identidade de mulher, identidade de homem, entre outras. Essas identidades são mutáveis e se movimentam na interação.

O que faz com que uma fala-em-interação seja institucional é o fato de abranger a realização de tarefas especiais e as identidades dos participantes serem coconstruídas para que essas tarefas sejam alcançadas. Por exemplo, sabemos que se trata de fala-em-interação institucional de atendimento médico quando existe um objetivo de examinar um paciente, então, a identidade de médico e a identidade de paciente vão sendo demonstradas, bem como a conversa se voltará para essa tarefa. Nesse sentido, a situação social não precisa ocorrer necessariamente no local "consultório médico", pois o que define a fala institucional são os objetivos e as identidades que são negociadas.

Uma interação institucional e, mais especificamente, interação de sala de aula, envolve: 1) meta, tarefa ou identidade institucional de pelo menos um dos participantes, o que comumente poderia ser a tarefa de ensinar e aprender e as identidades de professor e aluno; 2) limites particulares específicos ao tipo de evento, no caso os limites particulares da escola e da sala de aula; 3) procedimentos peculiares, também convencionalmente associados à instituição em questão, sala de aula (DREW; HERITAGE, 1992; CORONA, 2009).

Desse modo, o sistema de tomada de turno de fala e o reparo podem ser diferentes em uma fala institucional. Na conversa cotidiana, seus participantes podem ter objetivos a cumprir, mas esses não são pré-estabelecidos. Já a fala-em-interação institucional pode se desenvolver diferentemente, quando nessa situação social as ações são produzidas com fins característicos.

Analistas da conversa entendem a conversa na sala de aula como um tipo de conversa institucional que é empiricamente distinta do sistema da conversa cotidiana (SACKS, SCHEGLOFF \& JEFFERSON, 1974). Considerando que o sistema normal de conversa é gerido localmente, a igualdade de poder no sistema de trocas de fala, na sala de aula, a fala do professor é um sistema de intercâmbio de poder desigual, na qual professores têm direitos privilegiados para liderar tópicos e avaliar a qualidade 
da contribuição dos estudantes para uma interação emergente podendo assim dar uma segunda posição de reparação (MARKEE, 2000). (MARKEE; KASPER, 2004, p. 492)

Nesse sentido, temos algumas descrições da organização da falaem-interação em sala de aula. Uma dessas descrições, denominada Iniciação-Resposta-Avaliação (doravante IRA), foi descrita inicialmente por Sinclair e Coulthard (1975), que, aliás, não eram analistas da conversa. O padrão IRA consiste de o professor perguntar, o aluno responder e o professor avaliar a resposta, sendo uma sequência padrão, canônica e previsível para os participantes. $\mathrm{Na}$ sala de aula, habitualmente o professor faz uma pergunta, da qual ele sabe a resposta, para verificar se os alunos sabem responder corretamente, assim, após a resposta, ele avalia positiva ou negativamente. Dessa forma, está convencionalizado que são os professores quem iniciam e finalizam a sequência canônica. Um aluno pode, no entanto, adotar o papel do professor, ao iniciar e avaliar outro aluno ou mesmo o próprio professor na sala de aula, conforme mostram os dados de Jung e Gonzalez (2009), e, com isso, podemos ter "alunos sendo professores" e "professores sendo alunos".

Esse modelo é um dos pontos-chave para a questão das identidades trabalhadas no cenário pedagógico de sala de aula porque aponta diretamente para a negociação das identidades de professor e de aluno. Nessa organização, quem inicia e quem avalia a sequência demonstra uma identidade de "quem sabe", assumindo essa identidade negociada e sustentada na interação por quem responde e se deixa avaliar.

Segundo Garcez (2006, p. 70),

[...] o falante da iniciação - produtor da pergunta de informação conhecida - opera em um enquadramento que o torna insensível de certo modo, quase surdo mesmo, a tudo o que não seja aquilo que já estava no seu repertório mental de respostas esperadas, muitas vezes um conjunto unitário.

O professor elabora uma pergunta, cuja resposta ele já tem em mente, e espera que seus alunos respondam de acordo com o que ele 
espera, para que, assim, os possa avaliar positivamente. Caso o aluno não responda conforme o esperado, o professor pode avaliar negativamente ou, então, simplesmente, fingir não ouvir a resposta "errada", dita pelo aluno na situação social.

Por conseguinte, quando o professor está surdo às respostas dos alunos, ele pode estar sustentando certa identidade. Por exemplo, quando o professor ignora alguém na sala de aula, ele pode, com isso, ratificar o aluno como "mau aluno", ou estar confirmando a sua identidade de professor, a identidade de quem tem as respostas corretas.

A interação na sala de aula também pode acontecer fora do padrão IRA, quando há ou se estabelece um escopo crítico e democrático de construção de conhecimento. O'Connor e Michaels (1996) descrevem uma prática alternativa de organização da sala de aula e apresentam o revozeamento, ou seja, "um redizer do turno anterior para reexame pelo seu produtor, que recebe crédito pela autoria da articulação que produziu da questão cognitiva sob exame dos outros participantes da interação" (O'CONNOR; MICHAELS, 1996, p. 71). Nessa organização, o professor entusiasma todos os alunos a falarem, quando rediz o turno de um aluno para exame do próprio aluno que disse e para exame dos outros alunos ouvintes-participantes da interação. Assim, todos os alunos fazem asserções e contribuem para a discussão e para a construção da aprendizagem, e o professor ratifica todos os alunos, sustentando, com isso, sua identidade de professor.

Rampton (2006, p. 87-89) desenvolveu um estudo sobre a interação na sala de aula, explorando uma nova organização da comunicação. Segundo o autor, "uma nova ordem comunicativa combinando 'desordeiros no compromisso de aprendizagem' [p. 89] 'com a falta de ordem tradicional' [p. 87] pode ser posta em práticas em salas de aula urbanas." Ou seja, para o autor, a escola que quer que seus alunos fiquem quietos e ouçam o professor trabalhar o currículo está em crise. A sala de aula atual, contemporânea, apresenta conversas paralelas e alunos que falam de música funk, programas de TV, sites de relacionamentos, entre outros; essa sala de aula tem uma nova organização comunicativa.

Esta nova organização estaria substituindo a ordem tradicional na qual o professor dispunha de poder para determinar quando, 
onde e sobre o que os alunos teriam o direito de falar - isso quando a eles era franqueado esse direito - por uma organização em que os alunos também tomam a iniciativa e estabelecem suas preferências em relação ao que acontece na sala de aula. (AMARAL; FRANK, 2009, p. 56)

Dessa forma, a sala de aula tradicional está em crise e hoje o professor não tem mais o silêncio dos alunos. Na nova sala de aula, encontramos os alunos se posicionando diante dos tópicos trabalhados, fazendo relações com o que conhecem, desenvolvendo e até corrigindo o professor. Diante disso, professores e alunos estão tentando lidar com essa nova comunicação na interação.

O professor ainda busca dar conta do currículo, ainda quer transmitir os novos valores simbólicos consagrados historicamente e, em meio às diversas vozes se sobrepondo na sala de aula, acaba se amparando em qualquer contribuição de algum aluno que possa ser relacionada ao tópico em questão. A resposta do aluno à sua pergunta vem na forma de alguma música pop? OK, o professor ratifica a resposta e ainda a expande. A resposta trata de algum fato amplamente divulgado na mídia e apenas tangencia o tema em questão? OK, o professor trata do novo tópico, mas tenta voltar ao conteúdo da aula. A resposta vem em um fragmento de língua estrangeira de prestígio, presente no currículo? OK, o professor acolhe e ainda faz um breve comentário na língua estrangeira. A opção de aceitar a contribuição dos alunos, do jeito que vier, faz com que o professor não fique falando sozinho na frente do grupo. É isso ou nada. Ou, o que é ainda pior, não aceitar o que os alunos têm a dizer pode resultar em bate-bocas ou em agressões físicas, violências que se têm tornado notícia recorrente das salas de aula. (AMARAL; FRANK, 2009, p. 58)

A negociação entre professor e alunos, para fazer funcionar a interação na sala de aula, com as peculiaridades da nova ordem comunicativa própria da modernidade tardia, inclui considerar as individualidades de cada pessoa e a influência tecnológica do mundo. 
O professor deve estar atento à participação dos alunos e a essa "participação exuberante" (RAMPTON, 2006), na qual o aluno não se limita a responder as perguntas do professor, mas o aluno assalta o turno quando não é selecionado, sobrepõe voz com o professor e segue falando, entre outras.

A ACE está preocupada com questões de ordem da linguagem na interação, ou seja, ela concebe a linguagem como constructo social na/da relação entre os indivíduos na fala-em-interação. Nesse sentido, os participantes têm papéis ativos na ação social, sustentando, ratificando e sinalizando o contexto interacional e as relações identitárias em jogo na sequencialidade da conversa.

\section{Os dados}

As aulas analisadas neste estudo foram programadas e preparadas na disciplina de Estágio Supervisionado II de universidade do centrooeste do Paraná. A disciplina de Estágio Supervisionado II, do 4. ${ }^{\circ}$ ano do curso de Letras/Espanhol, possui 136 horas de aulas teóricas. Além disso, inclui 30 horas de aulas que devem ser ministradas em Ensino Médio de escola pública.

O trabalho de campo foi realizado em 2008. O corpus está composto de registro audiovisual e de notas de campo de 9 horas/ aulas do estágio de regência de uma graduanda do $4 .^{\circ}$ ano do curso de Letras/Espanhol: Sandra. Ela atua em duas turmas (3. ${ }^{a}$ série A e 3. ${ }^{a}$ série B) de uma escola pública, no Paraná. Joana é a professora que cedeu horas/aulas de suas turmas para que Sandra estagiasse na escola.

Os participantes da fala-em-interação das aulas analisadas são, portanto, Sandra (a estagiária), Joana (a professora das turmas), alunos (3. ${ }^{a}$ série $\mathrm{A}$ ou 3 . $^{\mathrm{a}}$ série $\mathrm{B}$ ) e a pesquisadora com a filmadora. O exame das aulas da estagiária foi realizado a partir da perspectiva da ACE, segundo a qual transcrição é análise. Portanto, a partir do ponto de vista da ACE, se fez uma transcrição de parte do material audiovisual coletado, seguindo o modelo do sistema Jefferson de transcrição ${ }^{2}$, criado pela analista Gail Jefferson e, posteriormente, usado pelos

${ }^{2}$ Ver LODER, L. L; JUNG, N. M. Fala-em-interação social: introdução à Análise da Conversa Etnometo do lógica. Campinas: Mercado de Letras, 2008. 
analistas da ACE (LODER, 2008). Esse sistema segue princípios que auxiliam a compreensão dos eventos transcritos na medida em que procura representar detalhes sonoros e visuais, proporcionando uma análise mais rica dos dados. Analiticamente, portanto, realizou-se análise de dados multimodais, como movimentação de braços e olhares. (GOODWIN, 1990; GOODWIN; GOODWIN, 2000; GOODWIN; GOODWIN; YAEGER-DROR, 2002; BULLA, 2007).

\section{A estagiária e os conflitos negociados na fala-em-interação}

A identidade de professora da estagiária é negociada entre os participantes da interação, com os alunos e com as professoras da turma. A presença da professora da sala, Joana, interfere na medida em que ela assume o seu papel de professora da turma. Veremos, no excerto 01, a seguir, que quando Joana toma o turno na sala de aula (linhas 11 e 13), interfere no status de "quem sabe" da estagiária ou no status de quem orquestra a fala-em-interação.

Excerto $01\left(3 .^{\mathrm{a}} \mathrm{A}\right)$

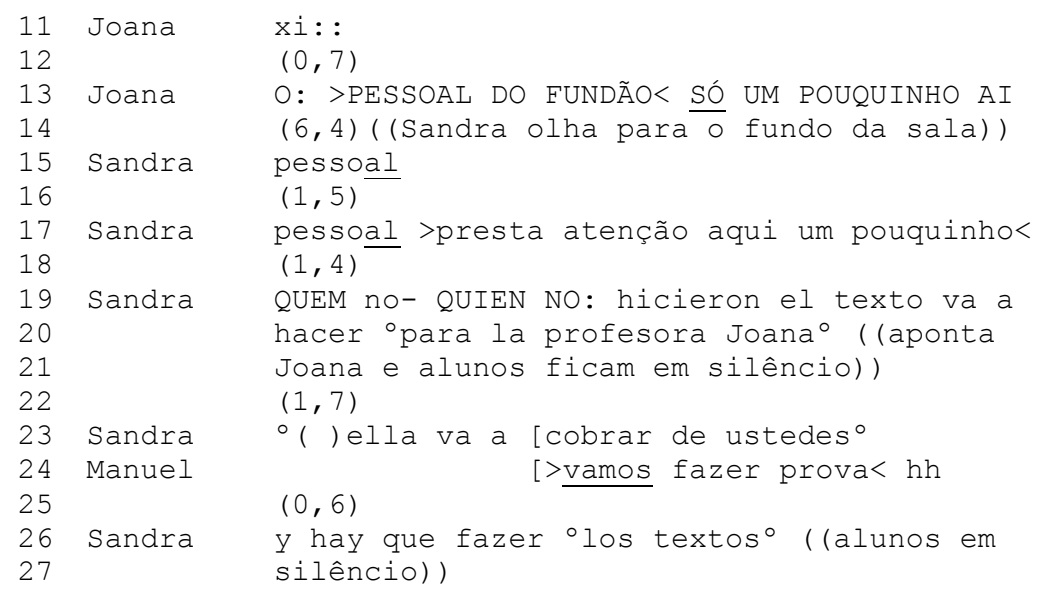

Nesse excerto, Joana assume o seu papel de professora da turma, uma ação ratificada na sequência pela estagiária. Joana pede silêncio 
aos alunos que estavam conversando (linhas 11 e 13). Ela eleva o tom de voz para que os alunos fiquem em silêncio, e Sandra olha para o fundo da sala e espera que os alunos façam silêncio (linha 14). É Joana quem pede aos alunos que fiquem quietos e prestem atenção na aula. Ela assume a identidade de professora da turma e Sandra reforça que obedeçam à Joana quando olha para os alunos em concordância com Joana.

Na sequência, Sandra toma o turno (linhas 15 e 17) para que os alunos olhem para ela e escutem-na. As professoras, Joana e Sandra, esperam que os alunos fiquem em silêncio (linhas 16 e 18).

Nesse excerto, Joana assume o seu papel de professora da turma, uma ação ratificada na sequência pela estagiária. Joana pede silêncio aos alunos que estavam conversando (linhas 11 e 13). Ela eleva o tom de voz para que os alunos fiquem em silêncio, e Sandra olha para o fundo da sala e espera que os alunos façam silêncio (linha 14). É Joana quem pede aos alunos que fiquem quietos e prestem atenção na aula. Ela assume a identidade de professora da turma e Sandra reforça que obedeçam à Joana quando olha para os alunos em concordância com Joana.

Na sequência, Sandra toma o turno (linhas 15 e 17) para que os alunos olhem para ela e escutem-na. As professoras, Joana e Sandra, esperam que os alunos fiquem em silêncio (linhas 16 e 18).

O turno seguinte é de Sandra que, ao orquestrar a fala-eminteração, diz: QUEM no- QUIEN NO: hicieron el texto va a hacer ${ }^{\circ}$ para la profesora Joana ${ }^{\circ}$ (linhas 19 e 20). Com o fato de Sandra ter pedido aos alunos que entreguem os trabalhos à Joana, Sandra ressalta que a professora da turma é Joana. Assim, ela reafirma a identidade de Joana como professora e a sua de estagiária. Percebemos que não fica claro quem irá corrigir os trabalhos, ou seja, Sandra pede que entreguem os trabalhos para a professora Joana, mas, ao mesmo tempo, exige que os alunos façam as atividades (linha 26). Parece tratar-se de uma ameaça, não somente ela irá avaliar os trabalhos que solicitou, mas também a professora da turma.

Cabe notar que entre as tomadas de turno de Sandra, Manuel sobrepõe voz com Sandra e diz dando risada: [ $>$ vamos fazer prova $<$ hb (linha 24). O aluno demonstra que não leva a sério o que Sandra está dizendo, o que se evidencia pelo seu riso no final da sua fala. Essa fala 
do aluno parece estar relacionada à fala de Sandra em sua apresentação, no primeiro dia de aula de seu estágio: "Espero que Joana no se importe, pero creo que para mi es mejor hacer la evaluación de ustedes atraves de los trabajos (...) Yo nunca formulé una prueba entonces para mi es más complicado, entonces quiero que ustedes entiendany hagan los trabajos que es para la nota" (Anotações de campo do dia 08/08/08). Com essa fala, Sandra negocia sua identidade de estagiária e não de professora, pois ela pede permissão à Joana para o tipo de avaliação que pretende realizar em suas aulas e destaca uma fragilidade sua: (...) Yo nunca formulé una prueba entonces para mi es más complicado.

Outro conflito, dessa vez entre estagiária e alunos, acontece em um evento ocorrido na sala de aula do 3. ${ }^{\mathrm{a}} \mathrm{B}$. O aluno Paulo está com uma dúvida, procura saná-la com Sandra (linhas 01, 03, 08), que não lhe apresenta a resposta da questão de número cinco. Por isso, por vários turnos, ele persegue essa resposta. O elemento principal é a persistência de Paulo em dizer que não sabe fazer o exercício e de Sandra em não apresentar ou levar o aluno à resposta. A atividade dada era sobre meio ambiente. Sandra pede para que os alunos leiam fragmentos de um texto e coloquem os parágrafos na ordem correta. Depois dessa tarefa, os alunos devem responder algumas questões sobre o texto.

Excerto $02\left(3 .^{\circ} \mathrm{B}\right)$






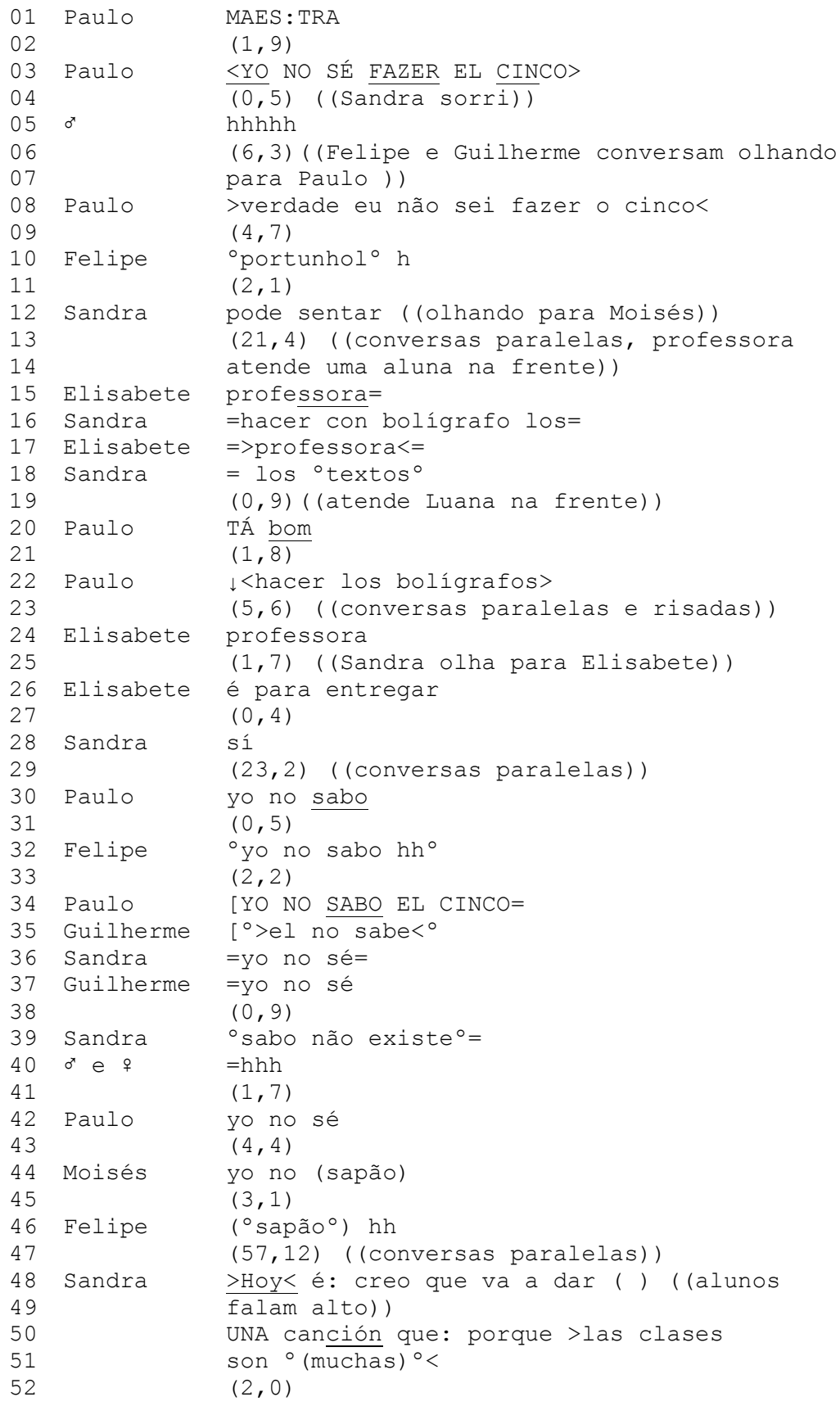




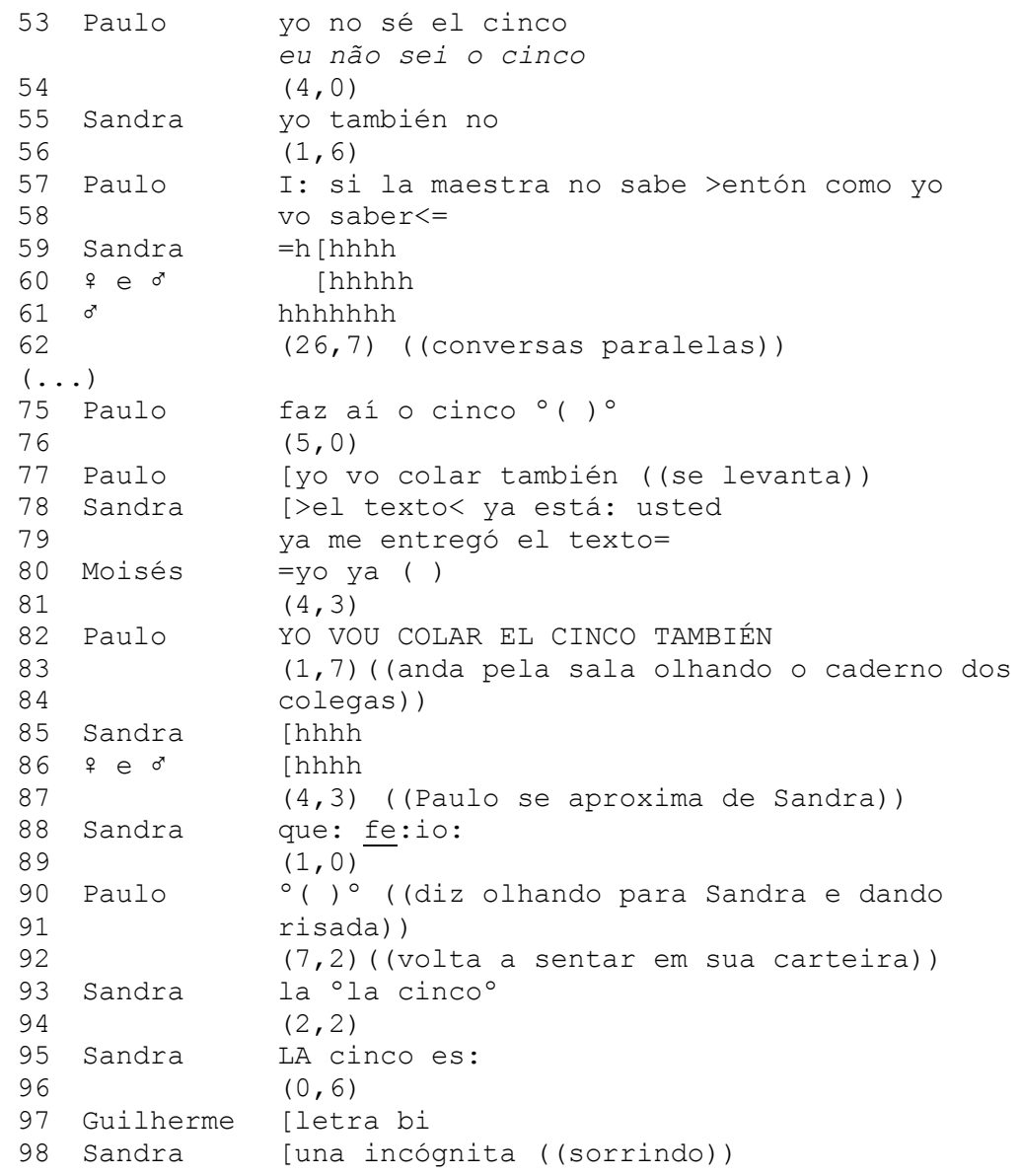

Paulo toma o turno, dizendo MAES:TR A <YO NO SÉ FAZER EL CINCO > (linhas 01 e 03). Ele pede ajuda à professora para que possa continuar resolvendo os exercícios. Assim, podemos entender que ele identifica um problema que o impede de seguir com suas atividades. No entanto, Paulo o faz de forma possivelmente irônica, haja vista que o tom de voz é alto e que a língua utilizada é a estrangeira. Sandra entende o tom de brincadeira, responde com um sorriso, assumindo uma identidade de quem não dá respostas prontas para os alunos (linha 04). 
Na sequência, conforme podemos ver na linha 30 do trecho do excerto repetido a seguir, Paulo diz novamente não saber fazer o exercício cinco. Nesse turno, no entanto, ele fala isso de forma diferente da dita anteriormente, ou seja, antes ele havia dito "no sé" (linha 03) e nesse momento diz e repete "no sabo" (linha 30 e 34). Paulo demonstra brincar com a língua espanhola e querer chamar a atenção da estagiária, já que antes havia utilizado o verbo corretamente.

Dito dessa forma, torna-se fonte de problema para Sandra que o corrige e o repara, pois Sandra diz =yo no sé= (linha 36) e logo depois explica: ${ }^{\circ}$ sabo não existe ${ }^{\circ}=($ linha 39). Assim, nesse momento, Sandra se posiciona como professora e Paulo sustenta dando recibo da correção, repetindo: yo no sé (linha 42).

Em seguida, na linha 53, Paulo toma o turno novamente, no local relevante para transição de turno, para repetir que não sabe fazer o exercício. Sandra finalmente responde para o aluno, dizendo que também não sabe fazer (linha 55). Paulo toma novamente o turno para dizer que se ela que é a professora não sabe então ele que é aluno não poderá saber (linhas 57 e 58).

$\mathrm{Na}$ fala de Paulo fica evidente que ele espera uma professora que saiba a resposta de todos os exercícios que passou. Os alunos e a própria estagiária, nesse momento, dão risada do que Paulo falou (linhas 59 e 60). O tom de brincadeira mascara, de certa forma, o conflito entre Paulo e a estagiária, pois não deixa que essa fala seja vista como uma depreciação ou que seja reprovada pela estagiária.

Os alunos dão risada em vários momentos porque Paulo fala na língua espanhola com Sandra. Isso pode ser observado quando o aluno segue tomando o turno na língua espanhola (linhas 22, 30, 34, $42,53,57,58,77$ e 82 ); e os alunos seguem dando risada disso e da brincadeira que Paulo faz (linhas 23, 32, 46, 60, 61 e 86).

Durante todo o excerto, Paulo toma o turno com frequência para pedir a resposta do exercício cinco, parecendo querer a atenção da professora e também dos colegas que dão risada dele. Ele testa a identidade de professora da estagiária, ao perceber que Sandra não responderá sua dúvida, persistindo e gerando um conflito ainda maior.

Quando surge um local relevante para transição de turno, Paulo pede para que Sandra dê a resposta dizendo: faz aí o cinco ${ }^{\circ}()^{\circ}$ (linha 75 no trecho repetido a seguir) e como não obtém resposta se levanta e 
toma o turno novamente para dizer [yo vo colar también (linha 77). A palavra "também" retoma o fato de que, como a estagiária não vai apresentar a resposta e como disse não saber a resposta, ele, como aluno, também não resolve a questão.

Sandra, em sobreposição à fala de Paulo diz: [>el texto < ya está: usted ya me entregó el texto $=($ linhas 78 e 79), selecionando Moisés para saber de suas atividades da sala. Com essa ação, Sandra demonstra indiferença em relação à dúvida de Paulo. Depois da resposta de Moisés (linha 80) para a estagiária, surge novo local relevante para transição de turnos e Paulo diz em tom bem alto, ainda em pé no meio da sala, $Y O$ VOU COLAR EL CINCO TAMBIÉN (linha 82).

Nesse instante, ele vai em direção à mesa onde está Sandra, olhando os cadernos dos seus colegas. Todos da sala dão risada (linha 86). Quando Paulo se posiciona na frente de Sandra, ele sorri e ela diz referindo-se a sua atitude que: fe:io: (linha 88). Paulo diz algo para Sandra que não foi possível identificar (linha 90) e volta para a sua carteira para se sentar. O conflito chega ao seu clímax. Sandra não apresenta a resposta solicitada por Paulo e ele resolve se movimentar na sala e enfrentá-la de frente, mesmo que em tom de brincadeira.

Com essa atitude tomada por Paulo, Sandra parece querer falar a resposta, quando diz: la \% cinco $^{\circ}$ (linha 93) e LA cinco es: (linha 95). Guilherme tenta responder dizendo [letra bi (linha 97), mas Sandra conclui sua fala não dando a resposta tão esperada por Paulo: [una incógnita (linha 98). Dessa forma, Paulo fica sem ter uma resposta para sua dúvida apresentada no início do excerto e perseguida durante toda a sequência.

Em termos de identidade, Paulo sustenta inicialmente a identidade de professora assumida por Sandra, mas deixa de sustentála na medida em que Sandra não apresenta a resposta que persegue. Instaura-se um conflito que atinge o seu clímax quando Paulo diz que vai "colar" dos colegas a resposta, ameaçando a autoridade de Sandra e de Joana. A estagiária, por sua vez, assume, aos poucos, que "não sabe" a resposta do exercício, e a professora da turma não se posiciona.

Vimos que a identidade de professora da estagiária é negociada com os alunos e com a professora da turma, e pode ou não ser ratificada. Vimos também que, nessa negociação, surgem conflitos e que as formas que a estagiária encontrou para resolver esses conflitos é ignorando, dissimulando e sorrindo da/na situação. 


\section{Considerações finais}

Este estudo mostra a dramaticidade da sala de aula contemporânea, na qual as identidades são questionadas, ratificadas, sustentadas, postas em xeque e afirmadas. Embora a estagiária tenha conseguido em poucos momentos orquestrar as tomadas de turno (quando tem o direito de seguir com o turno e quando seleciona os alunos como próximos falantes) e apesar de os alunos cosustentarem em alguma medida essa orquestração da estagiária, os conflitos se fizeram presentes. Em alguns momentos, a identidade de professora projetada pela estagiária não é ratificada, como na intervenção de Joana (excerto 1), nas pausas que indicam a espera de Sandra por silêncio (excerto 1), na insistência de Paulo em obter a resposta que buscava de Sandra (excerto 2), nas brincadeiras com a língua espanhola feitas por Paulo e ratificadas com risadas por colegas (excerto 2). Em outros momentos, a identidade de professora projetada pelos alunos não é ratificada, como na ação de Paulo de apresentar ter dificuldades e buscar uma resposta para a questão cinco (excerto 2).

Esses resultados que encontramos esclarecem que as identidades não são fixas e dadas a priori, mas construídas na interação, isto é, negociadas entre os participantes na interação a cada momento interacional. Sandra parece querer negociar não só a identidade de professora, mas, particularmente, a identidade de estagiária que atua por um pequeno período na turma, dando atividades avaliativas, sem respostas prontas e sem atender as dúvidas dos alunos, e, ainda, depende da ajuda da professora da turma para ter a atenção de todos. Ela consegue com pouca constância se assumir como a professora da turma, deixando que esta fluidez seja mais visivelmente exposta e sancionada pelos alunos. Ela atua em uma sala de aula dinâmica, contemporânea, e na negociação conjunta de identidades, ela fica na fronteira entre ser professora e ser estagiária.

Dessa maneira, gostaríamos de ressaltar que o estagiário em Letras deveria ter, em sua formação, oportunidades de discutir questões, como fala-em-interação, participação e identidade social, para se tornar capaz de articular as propostas teóricas com a prática educacional coconstruída na fala-em-interação em sala de aula. Está claro que essa junção deve compor a discussão sobre formação de professores, em 
especial formação de professores de espanhol, e deve ser feita com vistas a que o professor consiga posteriormente reconhecer e entender o que emergirá em sua sala de aula.

\section{Referências}

AMARAL, D.; FRANK, I. Novos arranjos. Educação, São Paulo, v. 12, p. 56-59, 2009.

BULLA, G. S. A realização de atividades pedagógicas colaborativas em sala de aula de português como língua estrangeira. 2007. Dissertação (Mestrado em Letras) - Universidade Federal do Rio Grande do Sul, Porto Alegre. 2007.

CORONA, M. D. Fala-em-interação cotidiana e fala-em-interação institucional: uma análise de audiências criminais. In: LODER, L. L.; JUNG, N. M. Análises de fala-em-interação institucional: a perspectiva da análise da conversa etnometodológica. Campinas: Mercado de Letras, 2009. p. $13-44$.

GOODWIN, M.H. He-said-she-said: talk as social organization among black children. Indianapolis: Indiana University Press, 1990.

.; GOODWIN, C. Emotion within situated activity. In: DURANTI, A. (Ed.). Linguistic Anthropology: a reader. Malden, MA: Blackwell, 2000. p. 239-57.

.; ___ Y YAEGER-DROR, M. Multi-modality in girls' game disputes. Journal of Pragmatics, v. 24, n. 10-11, p. 1621-1649, 2002.

DREW, P.; HERITAGE, J. Analyzing talk at work: an introduction. In: ; . (Orgs.). Talk at work: Interaction in institutional settings. Cambridge: Cambridge University Press, 1992. p. 3-65.

DURANTI. A. Antropologia lingüística. Trad. Pedro Tena. Madrid: Cambridge University Press, 2000. 
FERNÁNDEZ, F.M. El español en Brasil. In: SEDYCIAS, João (Org.) O ensino do espanhol no Brasil. Passado, presente, futuro. São Paulo: Parábola, 2005.

GARCEZ, P.M. A organização da fala-em-interação na sala de aula: controle social, reprodução de conhecimento, construção conjunta de conhecimento. Calidoscópio, v. 4, n. 1, p. 66-80, 2006.

- A perspectiva da Análise da Conversa Etnometodológica sobre o uso da linguagem em interação social. In: LODER, L.L; JUNG, N.M. Fala-em-interação social: introdução à Análise da Conversa Etnometodológica. Campinas: Mercado de Letras, 2008. p. 17-38.

JUNG, N.M.; GONZALEZ, P.C. A organização da tomada de turnos: socialização em sala de aula. In: LODER, L.L.; JUNG, N.M. Análises de fala-em-interação institucional: a perspectiva da Análise da Conversa Etnometodológica. Campinas: Mercado de Letras, 2009. p. 71-98.

LODER, L.L. O modelo Jefferson de transcrição: convenções e debates. In: .; JUNG, N.M. Fala-em-interação social: introdução à Análise da Conversa Etnometodológica. Campinas: Mercado de Letras, 2008. p. 127-162.

MARKEE, N.; KASPER, G. Classroom talks: an introduction. The Modern Language Journal, n. 88, 2004.

O’CONNOR, M.; MICHAELS, S. Shifting participant frameworks: orchestrating thinking practices in group discussion. In: HICKS, D. (Org.). Discourse, learning and schooling. Cambridge: Cambridge University Press, 1996. p. 63-103.

RAMPTON, B. Language in late modernity: interaction in an urban school. Cambridge: Cambridge University Press, 2006.

SACKS, H.; SCHEGLOFF, E. A.; JEFFERSON, G. Sistemática elementar para a organização da tomada de turnos para a conversa. Veredas, v.7, n. 1-2, p. 9-73, 2003. (Tradução de SACKS, H.; SCHEGLOFF, E. A.; JEFFERSON, G. A simplest systematic for the 
organization of turn-taking for conversation. Language, v. 50, 1974, p. 696-735).

SINCLAIR, J.; COULTHARD, M. Towards an analysis of discourse. Londres: Oxford University Press, 1975. 